ВОРОНЦОВ Сергей Алексеевич - доктор юридических наук, профессор кафедры процессуального права Российской академии народного хозяйства и государственной службы при Президенте РФ (119571, Россия, г. Москва, пр-кт Вернадского, 82, cmp. 1; raven_serg@таil.ru)

ПОНЕДЕЛКОВ Александр Васильевич - доктор политических наук, профессор; заведующий кафедрой политологии и этнополитики Российской академии народного хозяйства и государственной службы при Президенте РФ (119571, Россия, г. Москва, пр-кт Вернадского, 82, стр. 1; ponedelkov@ skags.ru)

\title{
О ВОЗМОЖНЫХ НАПРАВЛЕНИЯХ ПОВЫШЕНИЯ ЭФФЕКТИВНОСТИ ПРОТИВОДЕЙСТВИЯ ИДЕОЛОГИИ ТЕРРОРИЗМА
}

Аннотация. В статье на основе материалов социологического исследования, проведенного в августе сентябре 2019 г. в форме опроса экспертов, которым было охвачено 25 регионов Российской Федерации, авторы исследуют причины и условия, способствующие радикализации различных групп населения, прежде всего молодежи, анализируют существующие организационные формы пропаганды идеологии терроризма, пытаются сформулировать не использованные федеральными органами исполнительной власти, органами власти субъектов РФ и органами местного самоуправления резервы в организации противодействия идеологии терроризма.

Ключевые слова: идеология терроризма, радикализация населения, противодействие, экспертный опрос

B последние годы органам государственной власти и местного самоуправления при координирующей роли Национального антитеррористического комитета удалось минимизировать число проявлений террористического характера. Реализация комплекса мер в рамках Комплексного плана противодействия идеологии терроризма в Российской Федерации на 2013-2018 годы 1 позволила сформировать законодательные и организационные механизмы противодействия идеологии терроризма. Создано методическое и научное обеспечение данной деятельности, скоординирована деятельность органов государственной власти и местного самоуправления, общественных институтов и граждан по противодействию пропаганде идеологии терроризма. По информации директора ФСБ Александра Бортникова, в 2019 г. спецслужбы России смогли предотвратить 39 терактов. При этом 32 боевика были нейтрализованы, 679 - задержаны, 22 - были вынуждены отказаться от террористической деятельности. Также были ликвидированы 49 террористических ячеек, которые планировали атаки в различных регионах России.

Однако, несмотря на наметившуюся положительную динамику, возможность возникновения в настоящем и будущем террористических проявлений сохраняется, поэтому необходимо и дальше осуществлять меры по противодействию терроризму и обеспечению безопасности граждан, в т.ч. по предупреждению террористических актов, а также улучшать общественно-политическую и правовую ситуацию в стране 2 .

В целях дальнейшей реализации положений Стратегии национальной безо-

\footnotetext{
${ }^{1}$ Комплексный план противодействия идеологии терроризма в Российской Федерации на 2013-2018 годы. Доступ: https://www.nstu.ru/static_files/40742/file/Komplex_plan.pdf (проверено 12.03.2020).

2 Статистика террористической активности в России. 2019. Доступ: http://iminfin.ru/news/303statistika-terroristicheskoj-aktivnosti-v-rossii (проверено 12.03.2020).
} 
пасности Российской Федерации ${ }^{1}$, а также иных нормативных правовых актов в сфере обеспечения безопасности личности, общества, государства президент РФ В.В. Путин утвердил Комплексный план противодействия идеологии терроризма в Российской Федерации на 2019-2023 годы ${ }^{2}$.

В соответствии с п. 4.5.1. Комплексного плана на 2019-2023 годы, лаборатория проблем повышения эффективности государственного и муниципального управления Южно-Российского института управления - филиала РАНХиГС (г. Ростов-на-Дону) 22-23 ноября 2019 г. провела круглый стол с международным участием. В рамках круглого стола исследовались причины и условия, способствующие радикализации различных групп населения, прежде всего молодежи, анализировались новые организационные формы пропаганды идеологии терроризма, определялись не использованные федеральными органами исполнительной власти, органами власти субъектов РФ и органами местного самоуправления резервы в организации противодействия идеологии терроризма.

В процессе подготовки указанного научного форума в августе - сентябре 2019 г. по обсуждаемой тематике было проведено социологическое исследование в форме опроса экспертов, которым были охвачены 25 регионов РФ: г. СанктПетербург; Ростовская, Московская, Астраханская, Волгоградская, Курганская, Саратовская, Свердловская, Смоленская, Челябинская, Ярославская обл.; Алтайский, Камчатский, Краснодарский, Ставропольский края; республики Адыгея, Башкортостан, Дагестан, Ингушетия, Кабардино-Балкария, Карачаево-Черкесия, Карелия, Коми, Северная Осетия - Алания, Татарстан [Воронцов, Понеделков 2019].

К проведению исследования были привлечены эксперты, подавляющее число которых (96\%) владеют достаточными знаниями для участия в данном исследовании.

В том, что в современной России существует проблема пропаганды идеологии терроризма, убеждены около $80 \%$ экспертов. $96 \%$ участников исследования считают, что эта деятельность крайне опасна для личности, общества и государства, $3 \%$ полагают, что скорее опасна, не более $1 \%$ экспертов выбрали ответ «скорее не опасна».

По вопросу в отношении целей, преследуемых пропагандой идеологии терроризма, мнения экспертов разделились. Почти 50\% экспертов видят в качестве основной цели запугивание населения для подрыва существующей власти, инициируемое геополитическими противниками России. Около 1/3 экспертов считают, что пропаганда идеологии терроризма направлена на насильственное достижение политических целей сторонниками экстремистских организаций. Около $16 \%$ участников опроса считают, что целью пропаганды идеологии терроризма является запугивание населения, организуемое сторонниками религиозных экстремистских организаций.

Заслуживает более глубокого исследования тот факт, что 6,0\% экспертов видят в качестве цели пропаганды идеологии терроризма насильственное достижение политических целей сторонниками радикальной оппозиции. Видно, уроки, преподнесенные украинскими «майданами» как инструментарием свержения конституционного строя, еще не в полной мере осознаны обществом.

Анализируя характеристики, которые подходят к определению содержания понятия «пропаганда идеологии терроризма», в качестве первой ранговой

1 Указ Президента РФ от 31.12.2015 N 683 «О Стратегии национальной безопасности Российской Федерации». Доступ: https://base.garant.ru/71296054/ (проверено 12.03.2020).

2 Комплексный план противодействия идеологии терроризма в Российской Федерации на 2019-2023 годы. Утв. Президентом РФ 28.12.2018, № Пр-2665. Доступ: https://www.mchs.gov.ru/ dokumenty/2632 (проверено 12.03.2020). 
позиции эксперты указали насилие (82\%), на второй позиции - приверженность крайним взглядам (61\%), замыкает тройку ведущих характеристик нарушение закона (60\%).

Обращает на себя внимание выбор такой характеристики пропаганды идеологии терроризма, как «революционное движение», которую эксперты поставили на 4-ю позицию (48,0\%). Данное обстоятельство, на наш взгляд, вызывает озабоченность, т.к. и СМИ в публикациях о террористических и экстремистских проявлениях достаточно часто употребляют термин «революционеры», «политические заключенные» и др., романтизирующие облик правонарушителей, что может способствовать привлечению в ряды террористов маргинальной молодежи.

Ранжируя гипотезы о движущих силах пропаганды идеологии терроризма, около $90 \%$ экспертов поставили на первую ранговую позицию радикальные исламские группировки, находящиеся за пределами России. До 60\% экспертов видят в качестве движущей силы пропаганды идеологии терроризма зарубежные спецслужбы, столько же - радикальные исламские группировки, находящиеся на территории России.

Заслуживает внимание мнение $20,0 \%$ экспертов, что в качестве движущей силы пропаганды идеологии терроризма выступают психически неуравновешенные личности, которых, по мнению экспертов, больше, чем политических противников режима (19\%).

В числе субъектов противодействия пропаганде идеологии терроризма до 95\% экспертов поставили на первую ранговую позицию органы ФСБ России, на вторую позицию - Национальный антитеррористический комитет $(89 \%)$, затем органы МВД России (60\%). Таким образом, участники опроса видят основными субъектами противодействия пропаганде идеологии терроризма силовые структуры, занимающиеся борьбой с терроризмом, а также координацией антитеррористической деятельности.

Органы государственной власти и органы местного самоуправления, которые по определению должны быть ведущими субъектами противодействия пропаганде идеологии терроризма, таковыми в оценках экспертов не являются (чуть более $40 \%$ и около $30 \%$ соответственно).

При этом следует положительно отметить информированность 56,0\% экспертов о роли и месте антитеррористических комиссий в субъектах и муниципальных образованиях в противодействии пропаганде идеологии терроризма.

Оценивая динамику угрозы распространения идеологии терроризма в России, большинство экспертов считают, что ситуация остается стабильной (30\%) либо имеется тенденция к незначительному снижению (21\%). $7 \%$ экспертов считают, что угроза распространения идеологии терроризма существенно снижается.

Одновременно $27 \%$ экспертов отметили, что рост пропаганды идеологии терроризма не является значительным, а то, что заметен значительный рост данной угрозы полагают 5\% экспертов.

При оценке эффективности противодействия пропаганде терроризма в стране, регионе и муниципальном образовании эксперты указывают, что данная работа проводится не всегда эффективно (59\%, 49\%, 47\% соответственно). На недостаточный уровень данной работы указали $16 \%, 15 \%, 15 \%$ экспертов соответственно. В том, что работа по противодействию пропаганде терроризма в стране, регионе и муниципальном образовании ведется очень эффективно убеждены $21 \%, 29 \%, 31 \%$ экспертов соответственно.

Почти 2/3 экспертов, задействованных в социологическом опросе, считают, что полномочия органов власти в стране, в субъекте федерации и муниципальном образовании соответствуют задаче противодействия идеологии терроризма. 
Данное мнение большинства экспертов позволяет говорить о существенном совершенствовании в последние годы правовой основы обеспечения процесса противодействия идеологии терроризма. Однако $19 \%$ экспертов полагают, что имеющихся полномочий для решения указанной задачи недостаточно.

Мнения экспертов заметно разделились и по вопросу о соответствии объема бюджетного финансирования подразделений органов власти в субъекте федерации и в муниципальном образовании для решения задач противодействия идеологии терроризма. Лишь $19 \%$ экспертов удовлетворены размером бюджетного финансирования, 22\% считают, что установленное финансирование соответствует задаче не в полной мере, а $22 \%$ убеждены, что выделяемые средства не соответствуют качественному решению задач по противодействия идеологии терроризма.

Более единодушны эксперты оказались при ответе на вопрос: «Чувствуете ли Вы себя в безопасности от террористических угроз?» Так, полностью защищенными от террористических угроз ощущают себя $8 \%$ экспертов, $62 \%$ опрошенных выбрали вариант «скорее да», не уверены в своей безопасности от террористических угроз $19 \%$ экспертов, и $3 \%$ ощущают себя полностью незащищенными.

По мнению экспертов, уязвимость личности, общества, государства перед террористической угрозой обусловлена:

- либеральными взглядами;

- наличием национальных, религиозных проблем, имеющих для государства и общества важное значение и связанных с его самооценкой, духовностью, фундаментальными ценностями, традициями и обычаями;

- отсутствием единой государственной платформы (идеологии), объединяющей усилия всего населения России и органов государственной (муниципальной) власти в достижении стратегических целей;

- социально-экономическими проблемами, расслоением общества, социальным неравенством;

- навязыванием населению религиозных идей;

- ростом агрессии со стороны разного рода правозащитных организаций, финансируемых из-за рубежа, которая приобретает все более скрытый характер;

- безразличием основной массы населения к возможной террористической угрозе;

- недостатками воспитания в семье, неэффективной работой по воспитанию молодежи;

- применением террористами новых информационных технологий.

Достаточно категорично эксперты оценили обстоятельства, при которых можно оправдать для себя лицо, распространяющее идеологию терроризма. Так, около $80 \%$ экспертов полностью отвергают такую возможность, а $19 \%$ выбрали ответ «скорее нет». Остальные эксперты готовы оправдать такое лицо, если от данных действий зависит жизнь членов его семьи либо существует угроза жизни и здоровью близких. Ни один из экспертов не готов безоговорочно оправдать лиц, распространяющих идеологию терроризма.

Более $80 \%$ экспертов считают лиц, распространяющих идеологию терроризма, преступниками, 15\% выбрали вариант «скорее да».

92\% экспертов уверены, что деятельность лиц, распространяющих идеологию терроризма, должна пресекаться правоохранительными органами, остальные выбрали вариант ответа - «скорее да».

Мнения экспертов разделились при ответе на вопрос: допустимо ли в целях противодействия идеологии терроризма ограничивать права и свободы граждан во имя обеспечения общественной безопасности? 
Так, почти 70\% экспертов согласны с правом государства и общества защищать себя от пропаганды террористической идеологии с использованием методов, ограничивающих в установленных законом случаях права и свободы граждан. $19 \%$ экспертов не согласны с этим, остальные считают, что:

- ограничения могут допускаться только под жестким контролем со стороны прокуратуры, суда и гражданского общества, исключая использование данных ограничений в угоду тем или иным политическим силам;

- все зависит от того, в какой мере будут ограничиваться права и свободы и какие цели при этом будут реально достигаться, а не только декларироваться;

- ограничения допустимы при наличии надлежащего контроля со стороны надзорных органов за теми структурами, которые будут ограничивать права и свободу граждан.

Представляют практический интерес ответы экспертов на вопрос об уровне их информированности по проблеме противодействия идеологии терроризма для формирования представления о реально складывающейся ситуации в данной сфере.

Так, до 50\% экспертов считают, что они в достаточной мере владеют реальной ситуацией в рассматриваемой сфере. В противовес им $47 \%$ экспертов убеждены, что информации недостаточно для выдвижения обоснованных выводов о реальной ситуации с противодействием идеологии терроризма. $3 \%$ экспертов отметили, что не обладают необходимой информацией.

Недостаточная информированность экспертов по вопросам противодействия идеологии терроризма побудила проранжировать каналы получения ими сведений по данной проблеме.

На первую ранговую позицию эксперты поставили телевидение (более 80\%), на вторую - социальные сети (около 60\%), на третью - газеты и журналы (50-55\%). Также в числе источников искомой информации эксперты назвали встречи с представителями правоохранительных органов, передачи радиостанций и беседы с непосредственным окружением.

Заслуживает внимания информация, что за последние 3 года почти 2/3 экспертов не участвовали в работе программ повышения квалификации государственных (муниципальных) служащих по вопросам противодействия идеологии терроризма, $15 \%$ участвовали неоднократно, около $20 \%$ - единожды. Представляется, что с учетом сохранения в обозримый период террористических угроз и вызовов данная работа должна быть активизирована.

По оценкам экспертов, основной объем пропаганды идеологии терроризма реализуется с использованием возможностей Интернета (99\% - первая ранговая позиция). На вторую ранговую позицию эксперты поставили каналы религиозной пропаганды (речь идет об исламизме), реализуемой в т.ч. при содействии лиц, обучавшихся за рубежом (87\% и $80 \%)$.

Значимое место (74\%) в пропаганде идеологии терроризма эксперты отвели оппозиционным власти СМИ, на что должно быть обращено внимание надзорных органов. Разумеется, речь не может идти о введении цензуры, но уровень самоцензуры журналистов, как, впрочем, и уровень контрпропаганды, должен быть существенно повышен.

Несомненный интерес представляет мнение экспертов о том, какими мотивами руководствуются россияне, примыкающие к деятельности по пропаганде идеологии терроризма в своей стране. Так, по мнению экспертов, в большинстве случаев это происходит под влиянием меркантильных соображений (первая ранговая позиция - 85\%). Второй по значимости мотив, указанный экспертами, - идеологическое противостояние существующей власти.

В ряде случаев, по мнению экспертов, россияне участвовали в пропаганде 
идеологии терроризма под влиянием несправедливости и произвола власти, в основном на местах, а также из чувства безысходности.

Следует особо отметить мнение более половины экспертов, что примыкание к деятельности по пропаганде идеологии терроризма обусловлено стремлением некоторых молодых людей «прославиться» любой ценой, ибо, кроме комплекса Герострата, других путей попасть на телевизионные экраны и в сводки новостей у них нет.

Отвечая на вопрос, от кого в наибольшей степени зависит успешное противодействие идеологии терроризма в условиях современных политических процессов в России, эксперты поставили на первую ранговую позицию государство (92\%). Вторую позицию заняли СМИ (60\%), которые формируют общественное мнение. Далее следует население, общественные организации, религиозные деятели и политики.

С учетом живучести идеологии терроризма представляет интерес исследование причин, которые, по мнению экспертов, в наибольшей степени влияют на интерес граждан к идеологии терроризма. В качестве основных причин эксперты выделили падение уровня жизни; социально-экономические проблемы; напряженность в обществе и пессимизм; отсутствие постоянной работы и низкий заработок; криминализацию различных сфер жизни; «исламский фактор» и подрывную деятельность иностранных террористических организаций; неэффективную работу по идеологическому воспитанию молодежи; недостатки воспитания в семье.

В числе возможных направлений повышения эффективности противодействия пропаганде идеологии терроризма в регионе, которым следует уделить первостепенное внимание, эксперты на первую позицию поставили улучшение взаимодействия гражданского общества с правоохранительными органами (50\%). Вторым по значимости направлением эксперты видят улучшение всей системы воспитания молодежи и работы с семьями (44\%). На третьей позиции - повышение влияния гражданского общества (39\%).

Таким образом, эксперты видят пути усиления противодействия пропаганде идеологии терроризма не в укреплении силовой составляющей, реализуемой правоохранительными органами, а в реализации гражданских технологий, в совершенствовании воспитательной работы с молодежью, улучшении профилактической работы с лицами, подверженными идеологии терроризма, формировании у населения антитеррористического сознания.

В числе первоочередных мер, которые необходимо принять, чтобы снизить уязвимость молодежи от воздействия идеологии терроризма, эксперты указали активизацию работы в информационном пространстве, в т.ч. в социальных интернет-сетях (более 60\%), системное проведение на базе образовательных организаций антитеррористических воспитательных и культурно-просветительских мероприятий (60\%), реализацию мер, направленных на формирование религиозной, межнациональной терпимости, в т.ч. с помощью организации молодежных межрегиональных образовательных форумов (около 50\%).

Заслуживают внимания предложения о вовлечении молодежи в практическую работу по подготовке и реализации проектов антитеррористической направленности; привлечении к работе с молодежью религиозных лидеров и авторитетных политиков, несмотря на их оппозиционность; развитии системы обучения молодых кадров, участвующих в противодействии терроризму, информационном противостоянии в сети Интернет, в системной организации на базе образовательных организаций высшего образования научных семинаров, тренингов, курсов повышения квалификации.

Оценивая виды идеологии терроризма, представляющие наибольшую опас- 
ность, эксперты поставили на первую ранговую позицию идеологию радикального ислама (почти 90\%), далее следует идеология, связанная с попытками инспирирования «цветных революций» (более 60\%), и праворадикальная, фашистская и расистская идеология (40\%).

Следует положительно оценить, что более $90 \%$ экспертов готовы не только советовать, но и оказать содействие как граждане сотрудникам правоохранительных органов в противодействии пропаганде идеологии терроризма.

В числе причин, снижающих эффективность работы по противодействию идеологии терроризма, эксперты указали недостаточное взаимодействие государственных структур и общественных организаций, неэффективное международное сотрудничество, формализм, недостаточный профессионализм ответственных лиц, заниженный уровень ответственности должностных лиц за допущенные просчеты.

Результаты экспертного опроса позволяют уточнить причины и условия, влияющие на радикализацию различных групп населения, прежде всего молодежи, определить не использованные федеральными органами исполнительной власти, органами власти субъектов РФ и органами местного самоуправления резервы в организации противодействия идеологии терроризма.

\title{
Список литературы
}

Воронцов С.А., Понеделков А.В. 2019. Противодействие идеологии терроризма: по материалам социологических (полевых) исследований в Ростовской области. Противодействие идеологии терроризма: информационно-аналитические материалы круглого стола с международным участием. Ростов н/Д: Изд-во ЮРИУ РАНХИГС. С. 5-28.

VORONTSOV Sergei Alekseevich, Dr.Sci. (Legal), Professor of the Chair of Procedural Law, Russian Presidential Academy of National Economy and Public Administration (RANEPA) (bld. 1, 82 Vernadskogo Ave, Moscow, Russia, 119571; raven_serg@mail.ru)

PONEDELKOV Aleksandr Vasil'evich, Dr.Sci. (Pol.Sci.), Professor; Head of the Chair of Political Science and Ethnopolitics, Russian Presidential Academy of National Economy and Public Administration (RANEPA) (bld. 1, 82 Vernadskogo Ave, Moscow, Russia, 119571; ponedelkov@ skags.ru); Honored Scientist of the Russian Federation

\section{ON POSSIBLE DIRECTIONS FOR INCREASING THE EFFECTIVENESS OF COUNTERING THE IDEOLOGY OF TERRORISM}

\begin{abstract}
The article is based on materials of a sociological study conducted in August - September 2019 in the form of a survey of experts that covered 25 regions of the Russian Federation. The authors examine the causes and conditions that contribute to the radicalization of various groups of the population, primarily young people, and analyze existing organizational forms of propaganda of the ideology of terrorism. They are trying to formulate unused by the federal executive bodies, authorities of the constituent entities of the Russian Federation and local authorities reserves in the organization of counteraction to the ideology of terrorism.
\end{abstract}

Keywords: ideology of terrorism, radicalization of population, counteraction, expert survey 